B. Hawkins Ship Shape: Materializing leadership in the British Royal Navy

\title{
Ship-shape: Materializing leadership in the British Royal Navy
}

Beverley Hawkins

University of Exeter Business School

B.C.Hawkins@exeter.ac.uk

Human Relations DOI: 10.1177/0018726714563810

\begin{abstract}
In this article I contribute to posthumanist, actor-network influenced theories of leadership, drawing empirically on qualitative data collected at a Royal Navy shore establishment in Great Britain. I demonstrate how a fluid network of hybridized relationships between people and things affords shifting and multiple possibilities for making leadership matter. As configurations of actants evolve these affordances are altered, and the blackboxing processes hiding the material actants co-generating leadership effects are uncovered. A detailed explication of the politicised affordances within actor networks contributes to knowledge about how hybridized relationships co-enable possibilities for action that bring to life, reinforce, and call into question the human-centred, gendered, colonialist web of assumptions and practices through which Royal Naval personnel understand and enact leadership.
\end{abstract}

\section{Keywords}

Leadership, Organisational theory, Materiality, Sociomateriality, Actor Network Theory, Military Leadership, Affordances, Gender, Blackboxing, Hybridity 
B. Hawkins Ship Shape: Materializing leadership in the British Royal Navy

\section{Introduction: Locating the missing objects in leadership studies}

This article explores the complex interstices between leadership and materiality. My aim is to persuade the reader of the value of materializing leadership a) empirically, through illustrative vignettes and interview extracts, and b) conceptually and critically, by challenging and/or contributing to existing theoretical work on the process of leadership.

Exploring ethnographic observations and interview data collected at a Royal Naval Base in the United Kingdom, I draw on posthumanist perspectives (Braidotti, 2013, Latour 2007, 1994, Orlikowski 2007) to argue that material objects play an active role in generating, transmitting, legitimising and undoing meanings associated with leadership. I develop work on the hybridized relationships that generate leadership effects, such as Fairhurst and Cooren's (2009) exploration of leadership as the hybrid production of presence, by drawing on the concept of affordances: bundles of characteristics associated with material things, which emerge from the relationship of an object with other actants in a network (Gibson 1979, Bloomfield et al 2010). This requires that leadership scholars and practitioners develop an understanding of leadership as a politicised effect of practices that emerge from situated, performed relationships between people and things.

The 'thing-ness' of leadership is a relatively new preoccupation. The anthropologist Miller (2005: 5) points out the 'humility of things', suggesting that material objects are of great importance in our social lives, and yet appear so inconsequential that we neglect their implications. Recent scholarship is countering the long and rather curious absence of things within leadership studies (see, for example, Pullen and Vachhani's special issue of Leadership 2013, Ropo, Sauer and Salovaara, 2013, Ladkin and Taylor 2010, Fairhurst and Cooren, 2009, Fairhurst 2007, Sinclair 2005). Through the works of these authors, as well as 
B. Hawkins Ship Shape: Materializing leadership in the British Royal Navy

more broadly within organization studies (see the edited collections of Carlile et al 2013 and Leonardi, Nardi and Kallinikos 2012,) it is becoming clear that leadership is materialized through inter alia human bodily performances, architecture, clothing, and other artifacts. In the next section, I explore why the material in leadership has, until the last decade, rarely been articulated.

\section{Separating the transcendental from the terrestrial: The humility of the material within}

\section{leadership practice}

Prown (1982) argues that the significance of material objects for social practice has been neglected due to the Cartesian separation of the world into hierarchical binaries, e.g mind / matter, man / woman, leader / follower. As a result, lofty intellectual, cultural and spiritual pursuits are constructed as separate from and superior to baser, material things. The traditional leader/follower relationship assumes that the leader works with ideas, using distinctive intellectual abilities to motivate and inspire followers, who work with things as they bring the leader's goals and objectives to their material fruition (Collinson 2005).

This Cartesian schism between leader/sacred and follower/profane is pointed out in the critique of those strands of leadership scholarship that prioritise the skills, attributes and qualities of the leader as individual (Smircich and Morgan 1982, Cunliffe and Eriksen 2011). In contrast, post-heroic perspectives on leadership call this binary into question, regarding leadership as a process of meaning-making, in which individuals are united in the collective construction and enactment of a commonly, or at least loosely, shared understanding of what leadership is (Uhl-Bien 2006). These approaches draw on a range of theoretical perspectives, including phenomenology (Ladkin 2010, Cunliffe and Eriksen 2011) social constructionism (Uhl-Bien 2006) and discursive approaches (Fairhurst 2007), but share a conception of leadership as relational, emergent and socially constructed, rather than as the property of an 
individual (Cunliffe and Eriksen 2011, Collinson 2005). Leadership is conceived not as belonging to an individual with specific capabilities or traits, but as a social process emerging from the collective interactions of groups as they work together to identify and pursue a shared goal.

This leadership perspective is rooted in a processual ontology, in which reality is continually becoming, wrought into being over time (Langley et al 2013). Research has explored the identity work, through which social categories like man, woman, leader, or follower, are enacted stabilised or undermined, but never fully and completely secured (Butler 1999, Svenningsson and Larsson 2006), and the richly collaborative sense-making processes through which groups of individuals enact their environment and establish plausible courses of action (Weick 2012). Yet leadership is not a process in which individuals interact only with one another, nor is it one in which language is the only communication resource available to those who participate in it.

Where materiality was discussed by popular mainstream theorists (e.g. Schein 2004, Peters and Waterman 1982) objects were considered to play a functional and symbolic role in leadership. Artifacts are argued to 'reflect, consciously or unconsciously, the beliefs of individuals who made, commissioned, purchased or used them, and by extension, the beliefs of the larger society to which they belonged' (Prown 1982:2). However, by viewing objects as the tools of leaders or as the passive 'reflectors' of leadership values, we risk assuming that leaders are able to fully master both the objects themselves, and the way in which followers interpret the ideas and values that the objects are intended to represent. Such an approach is not entirely commensurate with a view of leadership as the effect of a precarious, emergent, culturally embedded process, a series of interactions and relationships with 
B. Hawkins Ship Shape: Materializing leadership in the British Royal Navy

unintended consequences, through which meanings and identities are generated, interpreted, rejected and altered, but never fully mastered. This requires an acceptance of objects as cogenerators of leadership effects, as is argued below.

\section{A posthumanist framework for materializing leadership effects}

In many areas of life, we talk of objects as if they are active participants in our activities. This is especially common where objects have impacts that we cannot attribute to human agency (Miller 2005). We say that computers 'crash', dishwashers 'break down' and automatic systems 'go on strike' (Latour 2007). We use phrases like this because the idea that objects perform certain actions for, with, or against us, is central to our meaning-making (ibid). Our activities - like leadership practices - take place in a web of relationships incorporating both people and objects, in which no single element has sovereignty over outcomes: 'people do not fly, nor does a B-52 bomber - the U.S. Air Force does' (Latour 1994:35).

By talking about the capabilities of objects, we are recognising the limits of human actions and intentions in constructing knowledge and mastering processes. Therefore, studying materiality is not about examining 'things', but examining the substance or mode of being of social relations (Cooren, Fairhurst and Hüet 2012). It focuses on the processes by which certain effects, like leadership, come to matter to us, or 'materialize' (ibid). We cannot study 'materiality' without studying social relations, and we cannot study social relations without understanding how the material gives substance to these relations and contributes to the development of new possibilities for action.

This focus on the relationships and activities between people and things has developed into a number of perspectives collectively known as 'posthumanist' (Braidotti 2013), all of which 
B. Hawkins Ship Shape: Materializing leadership in the British Royal Navy

seek to acknowledge the intertwining of the material and the social. These include relational materiality (Law 2004), sociomateriality (Orlikowski 2010) activity theory (Kaptelinin and Nardi 2006) and actor-network theory (ANT) (Latour 2007). Under ANT, practices like leadership are nested within a system or network of relationships between human and nonhuman 'actants' (Fox 2004, Latour 2007). A boardroom chair, for example, when prominently situated at the end of a table, surrounded by several other, smaller chairs, and when interacted with by individuals involved in leadership relationships, works within this network of actants to materialize assumptions and norms about relative status positions. The chair, in its relationships with people and other things, contributes to the (re)configuration of a particular relationship between leader and followers offering new possibilities to enact status differentials and therefore collaborate in the generation and legitimization of power imbalances and hierarchies amongst a board of directors.

Often, we fail to see the contribution of non-human actants to social relations, and fall back on attributing agency either solely to individuals or to groups of people, rather than to the variously arranged constellations of socio-material actants. This 'blackboxing' of non-human activity is brought to our attention only when a non-human actant fails in its duty to uphold the function of the network (Latour 1994). For example, when a dishwasher breaks down, the humans in a household suddenly realise that the dishwasher has previously contributed to the maintenance of a busy household routine (ibid).

Fairhurst (2007) points out the blackboxed material agencies involved in the accomplishment of charisma, by examining Rudi Giuliani's actions subsequent to the events of 9/11. She interprets charisma as a product of hybridized relationships between leaders, artifacts, and other individuals. In a critique of individualistic interpretations of charisma, Fairhurst's 
B. Hawkins Ship Shape: Materializing leadership in the British Royal Navy

contribution draws on Latour's (1994) notion of hybridity, a central concept of ANT in which human and non-human actants join together, resulting in altered possibilities for action.

Latour (ibid) demonstrates the mediating effect of hybridity using the (here, appropriately military) example of a human and a gun. When human and non-human actants form a hybrid 'gun-citizen' (ibid p32), the possibilities for action are changed. The goals of action may be modified: 'You had only wanted to hurt, but now, with a gun in hand, you want to kill' (Latour 1994 p32), and the shared responsibility for the action (gun+citizen+bullet) may be rendered opaque, so that only humans are thought to be responsible (hence the phrase 'guns don't kill, people do').

Orlikowski $(2007,2010)$ and Orlikowski and Scott (2008) have developed a stream of research examining the ontological 'entangling' of the social and the material, which they argue are wrought into being together, through practice (Orlikowski and Scott 2008). The distinctions between human agency ('citizen') and non-human passivity ('gun') are the result of 'agential cuts' (Barad 2007), separations made by discursively and materially situated human observers. Nonetheless the character of the interstices between the human and nonhuman remains the subject of debate. Sociomateriality has been varyingly interpreted as relating to the ontologically inseparable (Orlikowski and Scott 2008), interpenetrative (Barad 2007), relational (Orlikowski and Scott 2008) and embodied (Sinclair 2005) ways in which the social and the material are produced together. As Jones (2013, also Faulkner and Runde 2012) notes, each of these has specific, and sometimes differing implications for how we both research and theorise the material in organizing, some (though not all) of which debate centres on whether 'matter' pre-exists sociality, and the extent to and manner in which it is considered to have agency, as examined in more detail below. 
B. Hawkins Ship Shape: Materializing leadership in the British Royal Navy

\section{Mapping - and politicising - the contours of material agency}

ANT, and Latour's work on hybridity in particular, has been criticised for assuming an oversimplified, symmetrical view of agency, on the basis that humans can act consciously and with intentionality, whereas non-humans cannot. Pickering (1993) characterises this difference in terms of the 'accommodations' made by human agents in their efforts to negotiate the brute 'resistances' of non-human agents, which prevent or circumvent certain actions on the part of humans or other living things. He argues that this is not a return to dualism, emphasising the temporal, dialectical and emergent nature of human/non-human interactions, which means that although human/non-human agencies take different forms, they cannot be understood separately.

Kaptelinin and Nardi (2006) develop an activity-theory based asymmetrical positioning of agency, articulating three means by which people and objects can act on the world: conditional agency (both objects and humans can produce effects or 'conditions'), needsbased agency (humans and social entities like organizations must act in relation to social and physiological needs, but objects do not) and delegated agency (objects or humans can act on behalf of other humans). They offer an example of a cellphone, low on battery power, as a means of articulating the difference between their approach to agency and Latour's symmetrical approach (Kaptelinin and Nardi 2006:249). According to ANT, they argue, human agency is delegated to the phone, which 'acts' by beeping to ensure the human recharges it. But under activity theory, the phone does not choose to act: it is programmed to act. The human chooses to re-charge the phone rather than switching it off, throwing it away or cancelling her contract. 
B. Hawkins Ship Shape: Materializing leadership in the British Royal Navy

The limitation of this argument is that Kaptelinin and Nardi (2006) acknowledge these brute possibilities for action without taking into account the fact that the user-phone relationship emerges from within networked power relations and is situated within a wider constellation of relationships. For example, if the cellphone is maintained by the user for work purposes and is paid for by her employer, she might not have the option to turn it off or to cancel the contract. The implication is that forms of agency can only be assessed in context because their limits are not defined solely by their brute attributes, but also by the relationships in which they are embedded. Whittle and Spicer (2008 p614) argue that 'the so-called essential properties of a rock are achieved by the story in which they are narrated. What is a rock for an accident-prone stumbler becomes a sedimentary layer for a geologist' (or indeed a risk of grounding for naval personnel navigating a ship through shallow waters).

The concept of an affordance, a bundle of features that offers up certain possibilities for interaction (Gibson 1979), presents more a relational, processual, emergent way to understand the contribution of materiality to leadership. Water, (or a cellphone, or a rock) may not have consciousness, but it can be said to have potential: to make a difference (Cooren 2004, Pickering 1993) by affording certain opportunities for action, such as the possibility to engage in naval warfare. Whether or not water exists separately from human interaction, its affordances emerge only in conjunction with other material objects and artifacts like canons, ships, bodies, radar systems, ammunition and so on, and in conjunction with human intentionality. Bloomfield et al (2010) therefore argue that an object's affordances emerge in relation to the rest of the network and are similarly embedded in the power knowledge discourses that produce the configuration of that network and the intentions of actants within them. Following Bloomfield (2010), affordances are not essential categories, as Gibson (1979) originally suggested, but are formed out of the political 
B. Hawkins Ship Shape: Materializing leadership in the British Royal Navy

assumptions embedded in an actor network. Regardless of whether objects are ontologically prior, the affordances they co-generate are not. Therefore, a posthumanist, process-oriented account of leadership must avoid reducing agency to the various essences of objects, but cannot assume that the affordances of objects are inexhaustible (as suggested by Oliver 2005), because they are produced through power relations that produce and foreclose possibilities for action. Leadership is better understood as an effect of the temporal, emergent, and political tessellation, or following Leonardi’s (2012 p37) use of Taylor and Van Every's (2000) term imbrication - of human and material agencies. We cannot understand them by breaking them apart, because they function together: the whole is more than, or at least different from, the sum of the parts. The following section pays attention to how human bodies are imbricated in the performative materialization of leadership: through affording possibilities to invoke, reproduce and call into question leadership effects.

\section{Embodiment, gender and the disruption of leadership effects in actor networks}

The performed nature of power-knowledge relations (Fairhurst 2009, Butler 1999) necessitates an awareness of how physical (dis)ability, gender, gesture, and emotion afford possibilities to generate leadership effects (Küpers 2013, Bathurst and Cain 2013, Sinclair 2005). Sinclair (2005) notes that whilst bodily performances of leadership are produced through 'wider relations of power and discourse' that normalise assumptions about leadership in relation to gender and class, the sensuous physicality of bodies presents opportunities to disrupt and renew these discursive regimes. This is not a return to a human-centred perspective on leadership. As Küpers points out (2013:340), embodied leadership practices are not performed by self-contained actors, they are 'inter-practices', co-constituted, emergent, intertwining, generative relationships between the personal, the inter-personal, and the non-personal (ibid) which, through the shifting affordances for action they offer, can 
B. Hawkins Ship Shape: Materializing leadership in the British Royal Navy

normalise, undermine or reimagine knowledge about how leadership - and other identities like gender, or sexuality - are performed (Murh and Sullivan 2013).

ANT, in contrast, has been criticised for 'blackboxing' issues of gender (Sturman 2006) by marginalising those whose interactions with technology or other actants are not 'standard' (Wajcman 2000: 453), but there are others who see this as a consequence of the way ANT has been utilised in research accounts, rather than as a consequence of ANT itself (Berg and Lie 1995). Combining an awareness of hybridity with an appreciation of the politicised affordances offered, emergently, within constellations of performed relationships, offers a way to expose how these relationships can serve to undo, as well as naturalise masculinist and (dis)ablist assumptions about the accomplishment of leadership. It opens up an opportunity to examine the conditions that make any agency (human, non-human, and any hybrid configuration) possible.

The question at the heart of my empirical research therefore links affordances and actor network theory by asking how hybrid relationships afford politicised, multiple and shifting possibilities for materializing leadership in the British Royal Navy. The Royal Navy offers a rich empirical base from which to evidence these contributions. Woodward and Jenkings (2011) have demonstrated that military identities coalesce around shared experiences involving intimate knowledge of material things - the equipment of warfare, for example, or the geography of a specific theatre of operation. Military identities are made flesh through enactments of masculinity (Barrett 1996, Hale 2012, Godfrey et al 2012) and regimental discipline (Thornborrow and Brown 2009). Statues of generals on pedestals, rank slides and gold braid help to call into being the leadership hierarchy, cap badges and uniform styles materialize the affiliation of the wearer to a particular branch of a specific ship, regiment or 
squadron within the Navy, Army or Air Force respectively. These material artifacts are unique to their context, but the scholarship reviewed here suggests that the concept of leadership as a situated effect of hybridized practices is one that might apply within other corporate, institutional or public organizations.

\section{Method}

The Royal Navy of Great Britain was founded in the $16^{\text {th }}$ century, and is the naval warfare service of the British armed forces. I collected data during field observations and over 30 interviews conducted at a Royal Navy base that I call HMS NavalBase. The shore-based naval establishment is home to a major leadership-training base for the Royal Navy where ratings (enlisted personnel below warrant officer rank) and Non-Commissioned Officers (NCOs) receive leadership training prior to promotion to the next rank.

I conducted digitally recorded, semi-structured interviews, lasting an average of 60 minutes, with 8 officers, 3 warrant officers, and 7 ratings, of whom four were women. Discussions were structured around several themes including: naval ethos and culture, rites of passage, leadership training and development, the hierarchy of ranks and divisions between officers and sailors, and material objects of relevance to leadership. Objects that were the focus of discussion included uniforms, buildings, ships, ceremonial artifacts, flags, weaponry, paintings and statues. Often, the interviewees situated their reflections of an artifact within an experience that represented to them 'the real meaning of leadership', or that explained how and when they came to better understand the culture in which they were embedded.

For six consecutive nights, I moved into a 'Wardroom cabin' - the term for a bedroom in the Royal Navy's equivalent of an Officers' Mess. I shared all my mealtimes and evenings with 
B. Hawkins Ship Shape: Materializing leadership in the British Royal Navy

the resident officers, enabling me to make constant field observations and conduct additional unrecorded interviews with interested individuals and groups. During these informal interviews with 12 men and 3 women, which took place in the Wardroom and lasted up to three hours, I took extensive notes by hand. I ensured the written consent of every participant, whose identities and responses have been anonymised.

Miller (2010) emphasises the need for contextualised, empirical work on material culture, to enable the researcher to understand how object relations and meanings are locally situated. This is in line with an ethnographic approach to research, which espouses the observation of social interactions in their material context (Willis and Trondman 2000). My research afforded me countless opportunities to observe the texture of living and working on the base. I shadowed several Non-Commissioned Officers (NCOs) and officers working at the leadership-training academy, and was encouraged to ask questions at any time. I observed several leadership training exercises, and accompanied a group of Able Seamen on a visit to HMS Victory and HMS Warrior in Portsmouth, Hampshire. I recorded all my observations in a notebook, which I extended each evening together with my notes from the informal interviews, coding and cross-referencing each entry according to the themes that emerged during my visit. My coding processes gave rise to new questions, which I explored with the participants during subsequent discussions. As a result, the data collection, analysis and coding were an iterative process, involving working through 'first order concepts' (Van Maanen 1979) in the form of interview data and fieldnotes, to develop 'second order concepts' explaining the significance of or patterns within the data, in relation to theory. In this article, I have included data that I considered particularly helpful to the construction of an account, which is authentic (helping the reader understand what it was like to 'be there'), plausible (helping the reader make sense of what is happening) and critical (to sustain an 
B. Hawkins Ship Shape: Materializing leadership in the British Royal Navy

argument which might challenge assumptions about how, and by whom, leadership is produced). These are the criteria according to which Golden-Biddle and Locke (1993) argue ethnographic accounts should be judged.

Case studies do not contribute to knowledge by proving existing theories or identifying a representative sample. They are however valuable tools in exploratory research topics such as the materialization of leadership, and more generally in the research of complex social phenomena, because of the ability to generate rich data (Conger 1998). As Bryman (2004: 754) points out, 'qualitative research on leadership has brought to the fore several aspects of leadership processes that might otherwise have been relatively unexplored'. Where it is assumed, as here, that people collaborate to interpret the world around them and construct loosely shared understandings of reality through hybridised, performed relationships, an interpretive, situated method of investigation is not only justified, it is necessary (Lowe and Gardner 2000, Bryman et al 1996, Morgan and Smircich 1980).

My paper emphasises three ways in which materiality is threaded into leadership:

1) The Royal Navy's seafaring culture is enacted through the configurations of human and non-human actants that make up each ship. I emphasise the mutability and multiplicity of affordances generated within hybridised relationships, as they materialise, break down, and compete with new actants entering the network.

2) Within these interactions, I show that leadership is performed through the citation of normative values and assumptions and concurrent blackboxing processes that hide the agential contributions of non-humans, reifying individualistic, stereotypical performances of a ship-shape 'leader'. 
B. Hawkins Ship Shape: Materializing leadership in the British Royal Navy

3) In practice, the agential potential of the material, historically and geographically situated, is not separate from power but through the shifting and politicised affordances associated with material actants, is active in obscuring, de-legitimising and un-doing the gendered, politicised norms and assumptions embedded in the network within which leadership is enacted.

\section{Putting the ship into leadership: The network through which leadership is understood and enacted}

Throughout my research at HMS NavalBase, I was struck by overwhelming material references to ships, sea-faring and naval culture. Royal Navy land bases are never referred to as 'buildings' but as 'shore establishments', and as with all Royal Navy bases, the 'HMS' in HMS NavalBase refers to the title 'Her Majesty's Ship'. Similarly, names given to material artifacts and spaces inside the base make reference to ships and seafaring, with the effect of calling them, and their users, into being in a way that cites the seafaring heritage and ethos of being on board ship (Butler 1999). Royal Naval officers live and eat in a building filled with naval memorabilia, known as a 'wardroom' - the name given to officers' living quarters on board ship.

Life on base is punctuated by formal rituals and ceremonies, which were originally part of life at sea. Every day begins with a 'colours' ceremony, where a ship's ensign (colours unique to HMS NavalBase) and union flag are raised. A series of loud whistles signal everyone to stop their activities and remain silent whilst the ceremony takes place. A similar ceremony called 'sunset' or 'evening colours', takes place in the evening to lower the flags. As ANT indicates, relationships within networks are always in process, and must be repeatedly performed and 'cited' (Latour 2007) in order to maintain the network. Rituals like 
B. Hawkins Ship Shape: Materializing leadership in the British Royal Navy

colours, and the naming of everyday artifacts (living quarters, toilet facilities) after their shipbased equivalents, are vehicles for enacting the significance of 'ships' and 'being at sea' within networked relationships, embedded in the everyday routines at HMS NavalBase.

Here, a senior rate articulates the extent of the ship's significance:

Chief Petty Officer 1: The ship is referred to as 'she'... people will ask, 'what is the ship doing?' and that implies what you're doing, and so that's our base level. The ship, whatever the ship's routine is, that's our routine. Wherever the ship's deploying, we're deploying too, so when you are on a ship, everything is about her. [Extract from recorded interview]

The ship is not an inanimate object devoid of agency or power. She is active: she can deploy, she has a routine and a gender. The ship is a super-system of enacted relationships between people and things, relationships that Orlikowski (2007) terms 'sociomaterial' and that Latour (2007) describes as 'hybridised': a Ship-network, from which leadership effects are generated, sustained, legitimised and produced awry. The Ship (henceforth represented in italics to distinguish the ship-as-network-of-relationships, from other naval ships discussed in this article) is the means by which this interviewee makes sense of the Royal Navy's activities. It is a network to be to be feared, loved, respected, and most of all, to be part of. The feminization of the Ship was the key way that gender surfaced explicitly in my conversations with men and women participants. Where sharply tailored uniforms and physical training help to generate an unacknowledged (by my interviewees) form of masculinity in the 'disciplined bodies' of combat-ready military personnel (Godfrey et al 2012), the Ship contributes to the Royal Navy's masculinist discourses by acting as a visible, 
B. Hawkins Ship Shape: Materializing leadership in the British Royal Navy

explicitly feminine counterpoint (Barrett et al 1996, Berg and Lie 1995). Her femininity is significant because it demonstrates that gender in organizations does not materialize (come to matter) solely through practices associated with human bodies. The Ship is a vessel, designed to carry, protect and nurture those who sail in her. She commands pride and affection and her fragile capacity to carry safely must be intensely maintained and protected, even, as I demonstrate later, at a cost to the lives of individual personnel. This is why she encompasses 'everything', all that is meaningful to this sailor.

The number of actants in the Ship is not constant. Her relationships materialize and dissolve as time passes and locations change. Becoming part of the Ship is a vital part of the transition to member of the Royal Navy, as this Lieutenant vividly recalls:

Lieutenant 3: I can remember my first ship, I was eighteen years old and I was joining an aircraft carrier. My first ship, an aircraft carrier! and we were joining it from boat transfers. I was in this tiny little pass boat, coming up to this huge, huge, huge thing, and you got on board, and I was terrified... and it was fabulous and immediately you were kind of immersed into the whole thing... [in recorded interview]

This Lieutenant recognises that she has become immersed into something bigger than herself. She acknowledges that she became just one actant within the Ship: part of a giant, tangible 'terrifying', but 'fabulous' collective identity, part of 'the whole thing'. Membership of a Ship overwhelms every other kind of identifying category, such as rank or branch specialism:

Chief Petty Officer 2: Your attachment to ships overrule the branch badge and the uniform... if I have got a roomful of sailors, that room will probably be divided into 
B. Hawkins Ship Shape: Materializing leadership in the British Royal Navy

[sailors belonging to] HMS Liverpool, HMS Chatham, and The Ark Royal just because that is how [we] socially interact... [in recorded interview]

What, then, is the significance of this for leadership theory and practice? How might we put the Ship into leadership? My argument here is that the Ship represents the constellation of hybridized relationships within which leadership is accomplished, and within which sense is made as to what constitutes leadership, and what does not. To continue to produce leadership effects, the relationships between actants constituting the Ship must be continuously accomplished in ways that others recognise as leadership. When asked during interviews to talk about their experiences of leadership, officers and sailors used material actants from the Ship-network to make sense of what 'counts' as leadership. Here, an officer explains that the divisional system, the formal structure of leadership in the Royal Navy, is based on the historical requirements of ship's canons:

Lieutenant Commander 1: When you go on the Victory [warship from the Battle of Trafalgar, 1805], you will see that each gun will have - I can't remember how many people, depends on the size [of the canon], but an average of ten to fifteen peopleand that will be called a division, and that is where our divisional structure is based from... So you would have one officer in charge of...two guns, so they [the sailors operating those guns] would be his division and he would be responsible for their discipline, welfare, promotion and all that sort of stuff - and we still base it on that now. Even within our staff here, everyone has got a divisional officer [in recorded interview]. 
This officer describes how a micro-network of hybridized relationships between people (sailors) and material things (canons), nested within the larger Ship-network, affords the possibility of bringing the identities and associated responsibilities of officer/leader and rating/follower into being. Despite the fact that this web of relationships originated over 200 years ago and the number of personnel used to operate a gun on a warship has long since changed, the divisional system still exists, still 'matters', because it offers this possibility to materialize the formal hierarchical relationship between an officer and his/her sailors. Sailors line up in their 'divisions' (groups assigned to specific officers) on passing out after training, and for the divisions inspection each morning.

The continued existence of the divisional system confirms that the actants and relationships within the Ship materialize when they come to matter (Cooren, Fairhurst and Hüet 2012). When actants are not considered to contribute to an effect or outcome, they are subject to blackboxing. As Latour argues, within any network 'the number of actants varies...the composition of objects also varies, sometimes objects appear stable, sometimes they appear agitated, like a group of humans around a malfunctioning artifact /quasi-object / quasisubject'. (1994:36). For example, a nail in the hull of a ship might not be considered an actant unless it fails, when its contribution as an actant suddenly 'materializes' (or comes to matter) to other, human actants. Such constantly materializing and de-materializing constellations of actants produces different leadership effects at different times and locations, which are varyingly interpreted by human actants. The production of these effects is examined in further detail in the following section.

\section{'Closing the hatch': Materializing human-centred leadership effects}


B. Hawkins Ship Shape: Materializing leadership in the British Royal Navy

The conditions of leadership in the Royal Navy can be extreme - they can emerge quickly, have a human cost, and involve making huge sacrifices. Extreme leadership conditions are awarded tremendous mythological significance by personnel and are often reinvoked, or made to matter (Cooren Fairhurst and Hüet 2012), by men and women in my interviews and informal conversations. One evening in the Wardroom, this heated discussion emerged about what leadership 'really is', amongst a group of officers who expressed interest in my research:

Lieutenant 5: I'll tell you what leadership is! Closing the hatch on your oppo! That's leadership! [Sealing off a flooded area of the ship, which contains your 'opposite number', the individual who performs the same job as you on a different watch, so that s/he inevitably drowns]

Lieutenant Commander 1: [shudders] Ugh, I've done that before.

Lieutenant 4: No! Leadership is what you do AFTER you close the hatch on your oppo. It's after you do that, that's when you need to show leadership. [Group discussion, recorded in fieldnotes]

Whilst these naval offivers interpret leadership in different ways, they share an assumption that materiality is not a symbolic backdrop. If the material actants - the water, the hatch, the hull - perform in a way that is perceived to breach the integrity of the Ship, by leaking, breaking, seeping and so on, their affordances are altered: they enter into a new, more visible hybridised relationship with human actants, resulting in new possibilities to perform leadership effects (Latour, 1994, 2007). Material things play active roles, but this potential is not limited to one form of agency such as resistance to human intention (c.f. Pickering 1993) or an internal capacity to produce certain conditions (c.f. Kaptelinin and Nardi 2006). Their 
significance lies in the mutability and interdependence of the affordances they co-generate within hybrid relationships. Ships' panels leak, or are watertight depending on how other actants enable these affordances to materialise. Water may allow ships to float, but can also flood, depending on the affordances co-produced by other actants.

The importance of maintaining visible, aesthetic performances of leadership during times of crisis has been explored by Bathurst, Jackson and Statler (2010). My interviewees continued to re-materialize these performances in their debates, stories and recollections. The significance of 'closing the hatch' comes not from the frequency of its occurrence, but from the frequency of its re-imagining in informal banter and conversations (known as 'spinning dits') between sailors. This re-imagining occurs because of the possibilities for action thought of as 'leadership' presented by the oppo, the hatch, and the flooded water. Leadership is therefore not simply an atomistic individual performance, or a collaborative social endeavour, but an effect produced by appearing to control hybrid relationships with the aim of securing the integrity of a fragile Ship.

Certainly leadership-training programmes for sailors are as much concerned with the material, as the social. I witnessed groups of sailors work together, struggling to manoeuvre a series of objects - and each other - from one place to another using ropes and pulleys, without allowing the object to touch the ground. This leadership training presents opportunities to become part of an assemblage of material and knowledge (Haraway 1991), which comes into being through practice (Orlikowski and Scott 2008). It demands that sailors understand themselves to operate within the Ship's web of relationships, in which people and things act in fusion to produce visible leadership effects. The importance - and 
B. Hawkins Ship Shape: Materializing leadership in the British Royal Navy

method - of visible leadership practice is explained further in the following extract from an interview with a Chief Petty Officer:

Chief Petty Officer 3: People would have you believe you can't judge a book by a cover. That's not the way we see it in the Royal Navy. You very much can judge a sailor by his cover. Appearances matters... because, you walk into a room, they have got to see command presence, they have got to see leadership. You walk in, you've got to take charge, and that's from my ABs [Able Seamen] all the way up, and so your partnership has got to reflect that, the way you do your job has got to reflect that, the power and authority.

[AUTHOR]: And how do you see that, when somebody walks into a room? How do you see leadership?

Chief Petty Officer 3: In a military environment I see someone that walks in, straightbacked, looking smart, and looks you straight in the eye. It's like the firm handshake... [recorded interview $]$

These comments echo Fairhurst and Cooren's (2009) work on leadership as the 'hybrid production of presence'. Citing 'command presence', the appropriate normative values and assumptions that make one out to be a ship-shape leader, is a hybrid performance, produced by one's stance, gaze, and handshake and 'smart' uniform. Performing leadership in this way requires an apparent mastery of one's own physical presence, the production of a 'disciplined body' (Foucault 1977), which as Godfrey et al (2012) point out, is generated through power/knowledge regimes conveying a particular type of masculine physicality: one which goes unmentioned by my interviewees, but remains implicit in the strength of the handshake, 
B. Hawkins Ship Shape: Materializing leadership in the British Royal Navy

the straightness of the back, the commanding performance, and in the quest to master the fragile, feminized Ship.

Rather than supporting an atomistic, individualised or humanistic perspective on leadership, this indicates that the contributions of multiple actants involved in seemingly 'individual' leadership performances are effectively blackboxed or rendered opaque, preserving the illusion of the individual's mastery of leadership effects. Latour (1994) points out that within each black box are further black boxes containing previously unrecognised constellations of actants. Understanding the production of command presence requires that we see human flesh not as a single entity but a series of configurations of body parts, which materialize as actants when they become relevant to the production of leadership effects in conjunction with artifacts such as badges, rank slides and so on.

Command presence places demands on the body to accomplish a constellation of aesthetic performances by eyes ('look you in the eye'), hands ('the firm handshake',) legs ('walk in') and backs ('straight-backed'). Badges denoting rank are sewn onto the left sleeve of the sailors uniform, so leadership is referred to a 'left arm thing'. Indeed, 'left arm skills' (leadership skills) and 'right arm skills' (branch specific skills such as knowledge of mechanics or radar) were mentioned often during interviews and informal discussions. However, the reference to 'arm', not badge, indicates the contributions of the badge and sleeve to the leadership effect have been blackboxed. It is the flesh (the arm) of the leader, rather than the badge, which materializes, because of its capability to suggest that leadership is physically embodied by an individual. When I asked about the relevance of 'left arm skills', one Chief Petty Officer replied 'of course the badge [signalling leadership] is close to your heart, it defines what you are'. 
B. Hawkins Ship Shape: Materializing leadership in the British Royal Navy

The men and women I interviewed were scathing about the ability of 'scrambled egg' (the gold braid signifying rank which decorates an individual's hat and shoulders) to indicate leadership skill by itself, repeating often, 'Leadership has nothing to do with rank'. They reject the idea because leadership is not enacted by one or two actants. Rather, rank signifiers can only contribute towards an authentic aesthetic leadership performance alongside the practices of the left arm, heart, straight back, closed hatch, and so on.

The debate about 'closing the hatch' demonstrates that leadership performances are not always universally recognised as such by Naval Personnel. Moreover not all relationships generate identical implications for leadership practice. Tensions and inconsistencies within configurations of relationships can obfuscate the meanings and normative assumptions associated with leadership, as is explored is examined in the following section.

\section{Conflicting affordances: Enacting the Ship on a shore-based establishment}

Having shown how the Ship is constructed from hybridised, performed relations, in this section I argue that material things can also counter the ship-ness of life at HMS NavalBase by invoking a myriad of other ways of performing, thinking and being. Here, Royal Naval personnel work in offices, whose brick construction and solid foundations subvert the seafaring values embedded in the ships' ensigns and emblems that decorate them. From their office windows, personnel look out on parking lots occupied by the cars in which many commute to the base from home each day. The leadership training ground and high ropes course is surrounded by grass, not ocean. There is no sight of the sea or naval dockyard.

Every time a sailor drives onto base or enters the door of a building (instead of through a hatch), they enter into hybrid relationships (sailor+road, sailor+door), which materialize the implications of a land-based posting. The grass, the car park, the absence of sea also have 
B. Hawkins Ship Shape: Materializing leadership in the British Royal Navy

generative rather than constraining effects, but the possibilities for action that they generate are not necessarily associated with the cultural practices of sea-faring. As a result, the network of hybridised relationships at a shore establishment remains a partial performance of sea-faring culture, never quite ship-shape.

This partial enactment of seafaring has an impact on the ability of human actants to consistently engage in hybridised relationships that offer the possibility of producing leadership effects. Maintaining the integrity of a Ship is difficult when so many hybrid relationships afford other possibilities. Many participants told me that levels of identification and emotional commitment to a shore-based establishment were much lower than those felt towards a ship, as this Chief Petty Officer explains:

Chief Petty Officer 1: On a shore establishment it is a little bit harder to identify for me, because I don't think we ever truly feel about a shore establishment the way we do about a ship. [in recorded interview]

When enacted ashore, and clouded by other practices that evoke 'shore establishment', the collective relationships constituting the Ship are less precise in the production of recognised leadership effects than when they take place at sea. Many other personnel agreed that despite the presence of ship-related artifacts, ceremonies, and names in a shore-based establishment like HMS NavalBase, leadership effects seem more obscure than when they take place at sea, as this Lieutenant confirms:

Lieutenant 1: For me, leadership at sea is a lot crunchier - that's what I call it. It's fuzzier here [at HMS NavalBase]. Here it's a training establishment, at that point in 
B. Hawkins Ship Shape: Materializing leadership in the British Royal Navy

[the ratings'] career - it doesn't really cement into their mind, and cementing to them is what it is all about. As soon as they go to their first ship, and they are part of this small cohesive unit, this team, that they can see working, they can see leadership, they can see the rank structure working on board the ship. [in recorded interview]

On board ship, aspects of naval ethos like 'the team', and 'the rank structure' are embedded, or to use the lieutenant's materialization 'cemented', in networks of relationships that 'they [the ratings] can see working.' The performances appear more solid, more visible, because they are brought to life by the relatively coherent relationships of the Ship when it is at sea. A Chief Petty Officer explains this lack of emotional attachment to shore establishments in terms of what he calls 'pride of ownership', which he argues is an 'important element of leadership':

Chief Petty Officer 1: [if this room were my office], that scratch on the wall there [he points to a faint mark on the wall], I would make sure that is covered up and gone because I own this office. And when I hand this office over to the next guy, it should be immaculate. [It's] difficult to get that on a shore establishment but on a warship, that is your ship. If she is not working, the crew is not working. If she works really well, even if one element of her works well, it is pride for the entire ship and it is quite difficult to get that on shore. So [pride of ownership is] an important element of leadership [in recorded interview].

This Chief Petty Officer argues that pride of ownership requires an apparent mastery of the materiality of the Ship. It involves materializing 'immaculately' the relationships between actants that make up an effective Ship, so that she works really well'. A simple scratch on 
the wall calls into question the running of a 'tight ship'. Pride of ownership is therefore important to leadership because it maintains the illusion of individualistic mastery (or 'captaining') of the self and the Ship. A breakdown of any human or non-human actant (like a wall which develops a faint mark) reveals three things: firstly, the inability of individuals to master the material, secondly the contribution of material actants to the generation of social effects, and finally therefore, the inability of individuals to perform leadership by themselves.

Fox (2000: 683) suggests that actor-networks can break down at any 'human or non-human link'. However the alterations to the network produced by a change to an actant may be more nuanced than this. An apparently 'broken' actant, a scratched wall, for example, is still a generative actant, but rather than breaking down the network, the scratch on the wall contributes to an alteration of its effects. The scratch on the wall, hybridised with other actants, causes a shift in affordances so that pride of ownership is enacted awry, its materialization is skewed or as Butler (1999) puts it 'queered' - challenging the normative associations embedded in the possibilities afforded by the straight back, the closed hatch, the left arm, and the sailors' stories. Entangled in the collective and relational accomplishment of leadership effects, material things therefore play a role in obscuring, resisting, restraining or undoing the 'ideal' leadership performance by affording conflicting possibilities for action.

In ways similar to previous interview extracts, this participant's comments tie the fragility of the Ship to her gender, which like any accomplishment of femininity is precarious, always in process and simultaneously being undone (Butler 1999). Her 'vessel-ness' is not an essence, neither is it indicative of passivity. It is a product of a vast and fluid multiplicity of hybrid agencies, which ensure - and sometimes jeopardise - her safety, and that of those she carries. Her actants materialize and disperse, they break down and must be seen to be re-conquered 
B. Hawkins Ship Shape: Materializing leadership in the British Royal Navy

by the masculine disciplined bodies (Godfrey et al 2012) who own her. When networks of relationships afford incoherent or conflicted possibilities for action, they materialize as inauthentic ('not working'), and the 'pride', the illusion of individual mastery or 'ownership,' is lost.

This data reveals the challenges faced by human members of the Ship-network when engaging in 'showing' leadership. Despite the hybridized relationships that constitute their training, they are assessed as individuals on their leadership performance. Naval personnel must materialize a strong 'individual' command presence, an apparent mastery of the self and others in the network, but they are embedded in a web of hybrid relationships which change over time (as personnel come and go, as an immaculate wall develops a scratch), offering a multiplicity of possibilities for action: some of which are in line with normative assumptions, and some of which actively work to produce leadership awry.

Key to this incoherence is the fact that material objects such as buildings are produced and imported into the Ship-network over time. Networks stretch through time as well as space: historic artifacts and architecture materialize assumptions from the past within the present. Sailors continue to line up in their divisions, ordered by the demands of canons that no longer exist. Officers are trained in a building that permanently cites the Navy's most famous historic leaders: Drake, Hawk, Howe and Nelson, men whose identities are fused with building itself, their names carved into its façade in huge capitals. One (male) officer describes the college as:

Lieutenant Commander 3: '...set in granite, this sort of grinding bureaucracy, unchanging, unbending, unyielding, old-fashioned, male-dominated, white-maledominated... what does that say to somebody who is female and black that comes to 
B. Hawkins Ship Shape: Materializing leadership in the British Royal Navy

the organisation? ... They might consider this is a very introspective, unchanging organisation' [in recorded interview]

This is a Ship rich in material actants with origins stretching back through a history of colonialism and hegemonic masculinity (Barrett 1996): a Ship which is always in progress, but always being un-done: and which calls a cacophony of pasts into the present. Statues, figureheads, paintings, buildings, 'colours' and so on are not power-neutral: they form assemblages of knowledge/power relations invoking the eras in which they were designed. The possibilities that they afford for performing pride in the heritage of naval leadership carry with them the potential to materialize and perpetuate assumptions, rooted in that heritage, about colonialism, gender, (dis)ability or ethnicity. The affordances generated within the Ship, produced through time, place and power, therefore have implications for understanding how, for example, masculinist practices are perpetuated within military leadership (Barrett 1996, Hale 2012, Godfrey et al 2012).

\section{Closing remarks on the production of leadership effects}

In this article, I have suggested that the material be incorporated into accounts of leadership as process, which already view leadership as situated, performed, relational and collaborative (Cunliffe and Eriksen 2011). We cannot assume that material objects are simply the tools of leaders, or that they passively reflect leadership values, status and history. To do so is to 'blackbox' the agential role of the material in generating leadership effects, and to legitimise and reify assumptions about leadership as an heroic, individualistic endeavour.

Material actants co-produce leadership, which emerges not as an individualistic phenomenon but as a multitude of hybridised, powerfully-enacted, in-process relational effects produced 
B. Hawkins Ship Shape: Materializing leadership in the British Royal Navy

out of evolving, and sometimes conflicting, assemblages of specific body parts, technologies, clothing, and so on. Developing the ideas of authors who have indicated the hybrid production of leadership effects (Fairhurst 2007, Fairhurst and Cooren 2009, Küpers 2013), this article makes three specific contributions relating to the integration of the concept of affordances into actor-network led characterizations of leadership.

Firstly affordances help us to better characterise the agential role of actants within the hybridised generation of leadership effects. Rather than focusing on the essential properties of actants, recognising their situated affordances helps us understand how varied possibilities for enacting leadership within a network can emerge, mutate, co-exist and disperse. I emphasise the evolving, gendered, politicised affordances of material actants in the Ship, which shift across time as the inhabitants of networks change and as the power/knowledge regimes that produce them evolve. In co-operation with other actants, water produces affordances that make it float-able, but at other times flood-able. Statues of leaders invoke military might, but also 'say' things about the colonial past and heroism of naval warfare. From this, we can see that the contours of material agency are not limited to simple resistances to human accommodations as Pickering (1993) suggests. Furthermore an object's agential potential does not pre-exist power and cannot be categorised as an essence, separate from the relationships that produce it. Material affordances are multiple and mutable, generated and undone through hybridized relationships which themselves are the product of power/knowledge regimes that shift and disperse. These are the conditions that make any form of agency possible (Butler 1999).

Relatedly, an awareness of the shifting character of affordances develops understanding about the limits of 'blackboxing'. The work of material actants is often blackboxed so that 
leadership endeavours are viewed as the outcome of an individual (human) actor's leadership, rather than as the effect of hybrid relations. Blackboxing is a crucial process in the perpetuation of individualistic assumptions about leadership - but the shifting affordances generated within actor networks mean it is an impermanent, precarious one. When a hatch is closed, water floods, or a wall develops a scratch, previously blackboxed actants 'come to matter' (Cooren, Fairhurst and Hüet 2012) and the dynamic, nested nature of the Ship reveals itself. The production of leadership as an apparently individual performance is revealed to be an illusion, to which previously blackboxed constellations of body parts, badges, canons and other actants have contributed.

Finally, an awareness of how affordances are produced within the power relations embedded in an actor-network contributes to knowledge about how leadership effects are alwaysalready politicised. The possibilities for action that actants co-create are not power neutral, nor are they necessarily aligned with one another, or static in time and place. They repeatedly call into being ways of understanding leadership that are human-centred, gendered, colonialist, and anachronistic. Hybridized relationships afford ways of generating, but also resisting obscuring or undoing leadership performances. At HMS NavalBase they produce incoherent and unpredictable affordances for action, unrelated to the sea-faring culture in which assumptions about leadership such as 'pride of ownership' are grounded. The result is that leadership effects are 'fuzzier', or less coherently materialized, than when they take place at sea. The implication of this research for leadership scholarship is that it demands sensitivity to the material actants actively contributing to leadership effects. Looking at relationships between people tells us only part of the story: we need to look at the whole Ship, to learn more about how leadership is accomplished, gendered, legitimised, repeated, and, perhaps most significantly, worked awry. 
B. Hawkins Ship Shape: Materializing leadership in the British Royal Navy

The Ship might have its counterparts in other industries or organizations: one might similarly characterise a Hospital, a University, or the House of Commons as networks of hybrid relationships through which understandings about what it means to be not just a leader, but a nurse, a university lecturer, or a parliamentary representative are enacted through collaborative performances, involving, for example, needles and drips, lecterns and whiteboards, or the ballot box (Gherardi 2001). One avenue for future research might therefore be to explore the leadership effects afforded by other constellations of historically situated hybridized relationships. In particular, this article might serve as a point of departure for considering how leadership effects are materialized, 'queered' or obscured in relation to (or in spite of) other performative effects, such as gender, ethnicity or (dis)ability (Butler 1999). The contribution here illustrates that we can conceptualize the material reach of gender and other identity markers across networks, in ways that have implications beyond human embodiment, and which implicate the entire Ship. What is evident is that exploring the matter of leadership can contribute to our developing awareness of the complexities of organization, leadership and human relations. Indeed, by 'blackboxing' the roles of material actants in the production, gendering and undoing of leadership effects, leadership studies scholars risk perpetuating individualistic, mascunlinist and heroic assumptions about how leadership effects are generated.

\section{Acknowledgements}

The author would especially like to thank the participants of her study at HMS Navalbase for their engagement with and encouragement for this research.

She is extremely grateful to her colleagues at the University of Exeter Business School, Professors Hugh Wilmott and Eric Guthey and Dr Sally Riad for their help and guidance on 
B. Hawkins Ship Shape: Materializing leadership in the British Royal Navy

previous versions of this paper. She is also particularly indebted to Professor Gail Fairhurst and the three anonymous Human Relations reviewers, who endured several previous drafts and provided generous and thoughtful critique.

\section{Funding}

This research received no specific grant from any funding agency in the public, commercial or not-for-profit sectors.

\section{References}

Barrett FJ (1996) The Organizational Construction of Hegemonic Masculinity: The Case of the US Navy. Gender, Work and Organization 3(3): 129-142.

Barad, K (2003) Posthumanist performativity: Toward an understanding of how matter comes to matter. Signs 28(3): 801-831.

Bathurst R, \& Cain T (2013) Embodied leadership: The aesthetics of gesture. Leadership 9(3): 358-377.

Bathurst R, Jackson B and Statler M (2010) Leading Aesthetically in Uncertain Times. Leadership 6(3): 311-330.

Berg AJ and Lie M (1995). Feminism and constructivism: Do artifacts have gender? Science, Technology \& Human Values 20(3): 332-351.

Bloomfield BP Latham Y and Vurdubakis T (2010) Bodies, Technologies and Action Possibilities When is an Affordance? Sociology 44(3): 415-433.

Braidotti R (2013) The Posthuman. Cambridge, UK: Polity

Bryman A Stephens M and a Campo C (1996) The importance of context: Qualitative Research and the Study of Leadership. The Leadership Quarterly 7(3): 353-370. 
B. Hawkins Ship Shape: Materializing leadership in the British Royal Navy

Bryman A (2004) Qualitative Research on Leadership: A critical but appreciative review. The Leadership Quarterly 15(6): 729-769.

Butler J (1999) Gender Trouble: Feminsm and the Subversion of Identity. New York: Routledge.

Carlile PR Nicolini D Langley A and Tsoukas H (eds) (2013) How Matter Matters: Objects, Artifacts and Materiality in Organization Studies. Oxford: Oxford University Press.

Collinson D (2005) Dialectics of Leadership. Human Relations 58(11): 1419-1442.

Conger JA (1998) Qualitative Research as the Cornerstone Methodology for understanding Leadership. The Leadership Quarterly 9(1): 107-121.

Cooren F Fairhurst GT and Hüet R (2012) Why Matter Always Matters in (Organizational) Communication. pp296 - 314 in PM Leonardi BA Nardi and J Kallinikos (Eds.) Materiality and Organizing: Social Interaction in a Technologial World. Oxford: Oxford University Press.

Cooren F (2004) Textual Agency: How Texts Do Things in Organizations. Organization 11(3): 373-393.

Cunliffe AL and Erikson M (2011) Relational Leadership. Human Relations 64(11): 14251449

Fairhurst GT (2007) Discursive Leadership: In Conversation with Leadership Psychology London: Sage

Fairhurst GT and Cooren F (2009) Leadership as the Hybrid Production of Presence(s). Leadership 5(4): 469-490.

Faulkner P and Runde J (2012) On sociomateriality pp49-66 in PM Leonardi BA Nardi and J Kallinikos (Eds) (2012) Materiality and Organizing: Social Interaction in a Technological World. Oxford: Oxford University Press. 
B. Hawkins Ship Shape: Materializing leadership in the British Royal Navy

Foucault M (1977) Discipline and punish: The birth of the prison. New York: Random House LLC

Fox S (2000) Communities of Practice, Foucault and Actor-Network Theory. Journal of Management Studies 37(6): 853-867.

Gherardi S (2001) From Organizational Learning to Practice-Based Knowing. Human Relations 54(1): 131-139.

Gibson J (1979) The ecological approach to visual perception. Boston: Houghton Mifflin.

Golden-Biddle K and Locke K (1993) Appealing work: An investigation of how

ethnographic texts convince. Organization Science 4(4): 595-616.

Godfrey R Lilley S and Brewis J (2012) Biceps, Bitches and Borgs: Reading Jarhead's Representation of the Construction of the (Masculine) Military Body. Organization Studies 33(4): 541-562.

Hale HC (2012) The role of practice in the development of military masculinities. Gender, Work and Organization 19(6): 699-722.

Haraway DJ (1991) Simians, Cyborgs and Women: The Reinvention of Nature. New York: Routledge.

Jones M (2013) Untangling sociomateriality. pp 197- 226 in PR Carlile D Nicolini A Langley and H Tsoukas (Eds) (2013) How Matter Matters: Objects, Artifacts and Materiality in Organization Studies. Oxford: Oxford University Press.

Kaptelinin V and Nardi B (2006) Acting with Technology: Activity Theory and Interaction Design. Cambridge, MA: MIT Press.

Küpers WM (2013) Embodied inter-practices of leadership - Phenomenological perspectives on relational and responsive leading and following. Leadership 9(3): 335-357.

Ladkin D and Taylor SS (2010) Enacting the 'true self': Towards a theory of embodied authentic leadership. The Leadership Quarterly 21(1): 64-74. 
B. Hawkins Ship Shape: Materializing leadership in the British Royal Navy

Ladkin D (2010) Rethinking Leadership: A New Look at Old Questions. Gloucester, UK: Edward Elgar.

Langley A Smallman C Tsoukas H and Van de Ven AH (2013) Process studies of change in organizational management: Unveiling temporality, activity and flow. Academy of Management Journal 56(1): 1-13.

Latour B (2007) Reassembling the Social: An Introduction to Actor-Network Theory. Oxford: Oxford University Press.

Latour B (1994) On Technical Mediation: Philosophy, Sociology, Genealogy. Common Knowledge 3(2): 29-64.

Law J (2004) Actor Network Theory and After. Oxford: Blackwell.

Leonardi PM Nardi BA and Kallinikos J (Eds) (2012) Materiality and Organizing: Social Interaction in a Technological World. Oxford: Oxford University Press.

Leonardi PM (2012) Materiality, sociomateriality, and socio-technical systems: What do these terms mean? How are they different? Do we need them? In PM Leonardi BA Nardi and J Kallinikos (Eds) (2012) Materiality and Organizing: Social Interaction in a Technological World. Oxford: Oxford University Press.

Lowe KB and Gardner WL (2000) Ten years of The Leadership Quarterly: Contributions and challenges for the future. The Leadership Quarterly 11(4): 459-514.

Miller D (2005) Materiality. Durham, NC: Duke University Press.

Miller D (2010) Stuff. Cambridge: Polity Press.

Morgan G and Smircich L (1980) The case for qualitative research. Academy of Management Review 5(4): 491-500.

Muhr SL and Sullivan KR (2013) "None so queer as folk": Gendered expectations and transgressive bodies in leadership. Leadership 9(3): 416-435. 
B. Hawkins Ship Shape: Materializing leadership in the British Royal Navy

Oliver M (2005) The problem with affordance. Educational Technology and Society 2(4): $402-413$.

Orlikowski WJ (2007) Sociomaterial Practices: Exploring Technology at Work. Organization Studies 28(9): 1435-1448.

Orlikowski WJ (2010) The sociomateriality of organisational life: considering technology in management research. Cambridge Journal of Economics 34(1): 125-141.

Orlikowski WJ and Scott SV (2008) Sociomateriality: Challenging the Separation of Technology, Work and Organization. The academy of management annals 2(1) 433-474. Peters T and Waterman R (1982) In search of excellence: Lessons from America's best-run corporations. New York: Warner.

Pickering A (1993) The mangle of practice: Agency and emergence in the sociology of science. American Journal of Sociology 99(3): 559-589.

Prown JD (1982) Mind in Matter: An Introduction to Material Culture Theory and Method. Winterthur Portfolio 17(1): 1-19.

Pullen A and Vachhani S (2013) The Materiality of Leadership. Leadership 9(3): 315-318. Ropo A Sauer E and Salovaara P (2013) Embodiment of leadership through material place Leadership 9(3): 378-395.

Schein EH (2004) Organizational Culture and Leadership. San Fransisco: Jossey-Bass.

Sinclair A (2005) Body Possibilities in Leadership. Leadership 1(4): 387-406.

Smircich L and Morgan G (1982) Leadership: The Management of Meaning. Journal of Applied Behavioural Science 18(3): 257-273.

Sturman S (2006) On Black-boxing Gender: Some Social Questions for Bruno Latour. Social Epistemology 20(2): 181-184.

Svenningsson S and Larsson M (2006) Fantasies of leadership: Identity work Leadership 2(2): 203-224 
B. Hawkins Ship Shape: Materializing leadership in the British Royal Navy

Taylor JR and Van Every EJ (2000) The Emergent Organization: Communication as its site and surface. London: Routledge

Thornborrow T \& Brown AD (2009) 'Being regimented': Aspiration, discipline and identity work in the British Parachute Regiment. Organization Studies 30(4): 355-376.

Uhl-Bien M (2006) Relational Leadership Theory: Exploring the social processes of leadership and organizing. The Leadership Quarterly 17(6): 654-676.

Van Maanen J (1979) The fact of fiction in organizational ethnography. Administrative Science Quarterly 24(4): 539-550.

Wajcman J (2000) Reflections on gender and technology studies: in what state is the art?

Social Studies of Science 30(3): 447-464.

Weick K (2012) Organized sensemaking: A commentary on processes of interpretive work. Human Relations 65(1): 141-153.

Whittle A \& Spicer A (2008). Is actor network theory critique? Organization Studies 29(4): 611-629.

Willis P and Trondman M (2002) Manifesto for Ethnography. Cultural Studies $\leftrightarrow$ Critical Methodologies 2(3): 394-402

Woodward R and Jenkings KN (2011) Military Identities in the Situated Accounts of British Military Personnel. Sociology 45(2): 252-268.

\section{Acknowledgements}

The author would especially like to thank the participants of her study at HMS Navalbase for their engagement with and encouragement for this research. She is extremely grateful to her colleagues at the University of Exeter Business School, Professors Hugh Wilmott and Eric Guthey and Dr Sally Riad for their help and guidance on previous versions of this paper. She is also particularly indebted to Professor Gail Fairhurst and the three anonymous Human Relations reviewers, who endured several previous drafts and provided generous and thoughtful critique.

\section{Author Biography}

Beverley Hawkins is a lecturer in Leadership Studies at the University of Exeter Business School, University of Exeter, UK. She has a longstanding interest in the collaborative aspects and identity work processes embedded in organizational life, particularly in relation 
to teamwork and leadership. Dr Hawkins has published work examining gendered concertive control processes in self-managed teams, resistance to corporate culture and the experience of liminal transition in doing, learning about and teaching leadership. She was a co-investigator on an award-winning ESF-funded project entitled 'Clear about Carbon', examining the challenges of leading transitions towards low-carbon business practices in Cornwall. Her research can be found in refereed journals including Management Learning, Sociology and Gender, Work and Organization, and she has co-authored a book entitled Exploring Leadership: Individual, Organizational and Societal Perspectives with colleagues from the Centre for Leadership Studies at the University of Exeter Business School. [Email B.C.Hawkins@exeter.ac.uk]

\section{Corresponding author:}

Beverley Hawkins

Business School

University of Exeter

Xfi Building

Streatham Campus

Exeter University

Exeter

EX4 4ST

United Kingdom

B.C.Hawkins@exeter.ac.uk 